\title{
Ethnic identity and discrimination among children
}

\author{
Jane Friesen ${ }^{\mathrm{a}, *}$, Jasmina Arifovic ${ }^{\mathrm{a}}$, Stephen C. Wright ${ }^{\mathrm{b}}$, Andreas Ludwig ${ }^{\mathrm{a}}$, Lisa Giamo ${ }^{\mathrm{b}}$, \\ Gamze Baray ${ }^{c}$ \\ ${ }^{a}$ Department of Economics, Simon Fraser University, Canada \\ ${ }^{\mathrm{b}}$ Department of Psychology, Simon Fraser University, Canada \\ ${ }^{\mathrm{c}}$ Department of Psychology, Bilkent University, Turkey
}

\section{A R T I C L E I N F O}

\section{Article history:}

Received 15 January 2011

Received in revised form 4 June 2012

Accepted 7 August 2012

Available online 15 August 2012

\section{JEL classification:}

D64

J15

PsycINFO classification:

3020

3560

Keywords:

Social identity

Children

Altruism

Discrimination

\begin{abstract}
A B S T R A C T
We engaged over 430 Canadian children in a series of activities designed to reveal their evaluations of three ethnic groups (White, East Asian and South Asian), their identification with these groups, and their behavior towards them in a dictator game. Our experiments took place at the children's schools during their normal school day, allowing us to evaluate the salience and effects of ethnic identities on economically relevant behavior in an important natural setting. We find that children from the dominant White category have a clear sense of White ethnic identity, and tend to favor White recipients in the dictator game relative to East Asian or South Asian recipients. Minority East Asian children reveal a more complex ethnic identity; they perceive themselves to be equally similar to White and East Asian children. Unlike Whites, East Asian children do not favor recipients from their own East Asian category, nor do they favor recipients with whom they tend to identify. If anything, East Asian children show out-group favoritism.
\end{abstract}

(c) 2012 Elsevier B.V. All rights reserved.

\section{Introduction}

A large empirical literature in social psychology and economics demonstrates that individuals tend to favor members of groups with whom they associate themselves. Social identity theory, which posits that individuals place themselves and others in groups and make comparisons across groups, provides a conceptual framework for understanding intergroup relations and, particularly, this tendency for individuals to favor members of "in-groups" with whom they identify (Tajfel \& Turner, 1986).

Much of the evidence for what has been referred to as the in-group bias effect has come from experiments in which behavior is compared across neutral conditions and conditions where identity is made more salient, either by inducing artificial identities in the "minimal group paradigm" (Tajfel \& Turner, 1986), or by priming natural identities. Recent examples of minimal group studies involving economic games include Chen and $\mathrm{Li}$ (2009), who find greater charity towards and less envy of in-group members, a stronger tendency to forgive and weaker tendency to punish bad intentions of in-group members, and a greater likelihood of choosing social-welfare-maximizing actions when participants are matched with an in-group member. Studies that involve priming natural social identities include Shih, Pittinsky, and Ambady (1999), Benjamin, Choi,

\footnotetext{
* Corresponding author. Address: Department of Economics, Simon Fraser University, Burnaby B.C., Canada V5A 1S6.

E-mail address: friesen@sfu.ca (J. Friesen).
} 
and Fisher (2010) and Benjamin, Choi, and Strickland (2010), as well as many studies in social psychology. Evidence that in-group bias is pervasive with respect to a wide variety of naturally-occurring groupings comes from studies that find preferential treatment towards in-groups in the context of real, unprimed social groupings, including college fraternities (Kollock, 1998), tribes in Papua New Guinea (Bernhard, Fischbacher, \& Fehr, 2006), Swiss Army platoons (Goette, Huffman, \& Meier, 2006), schools (Fehr, Bernhard, \& Rockenbach, 2008), and groups defined by a variety of personal characteristics (Ben-Ner, McCall, Stephane, \& Wang, 2009). Racial and ethnic bias has also been found in dictator games among South African subjects (Burns, in press) and among Israeli subjects (Fershtman \& Gneezy, 2001).

This study explores in-group bias in children's altruistic behavior. Studies involving children can inform our understanding of the developmental processes associated with in-group bias, and may shed light on the evolutionary forces that have shaped these social preferences (Fehr et al. 2008). Previous research provides mixed evidence about whether children's altruistic behavior is characterized by in-group bias. Fehr et al. (2008) find that children aged three to eight are more likely to choose an egalitarian allocation when dividing resources between themselves and an in-group member (defined as a child who attends the same pre-school, daycare or school) than with an out-group member. McGillicuddy-de Lisi et al. (2006) find no evidence of in-group bias in allocations by young elementary school children to black and white story characters. Goeree, McConnell, Mitchell, Tromp, and Yariv (2010) find that dictator offers to schoolmates among girls aged ten to twelve are explained by social distance to the recipient, as measured by school friendship networks; however, observable characteristics of the recipient, including race, play little or no direct role in determining their allocations. Two studies that use the minimal group paradigm with children also produce mixed results. Spielman (2000) finds that Kindergarten children allocate more resources to in-group than out-group members only when they are competitively primed; Gummerum, Takezawa, and Keller (2009) find that sixth grade students exhibit in-group bias in a series of economic games, but second grade children do not.

We examine children's altruistic behavior towards children from phenotypically different ethnic groups. Over 430 children between the ages of five and eight, belonging to three different ethnic categories (White, East Asian and South Asian) and attending public school in Vancouver, Canada participated in our study in 2007 and 2008. We engaged these children in a series of activities that draw from both social psychology and experimental economics and are designed to reveal their evaluations of other children from each of these three ethnic categories (i.e. White, East Asian and South Asian), their identification with children in these categories and their behavior towards them. These activities were conducted as a series of games during the regular school day in the children's normal school environments, allowing us to gauge their intergroup attitudes and behavior in relation to naturally occurring ethnic categories in an important natural setting.

The literature on in-group bias described above addresses a joint hypothesis: that the boundaries of in-groups and outgroups coincide with the measured categories (e.g. school, ethnicity, artificially-induced group), and that individuals behave differently towards in-group and out-group members. Similarly, we would expect participants in our study to favor members of their own ethnic group if both component hypotheses are satisfied; that is, if ethnicity is salient to children's ethnic identities at this developmental stage, and if social identity shapes children's behavior as has been demonstrated in the case of adults. If, however, this joint hypothesis is rejected, we can gain greater insight into the relationship between social identity and altruism by testing each component of it separately. Fong and Luttmer (2009), for example, find that measured identification with one's own racial group, rather than race per se, is a key determinant of discrimination by blacks and whites in charitable giving. We adopt this approach, and investigate whether ethnic identities coincide with ethnic categories, and whether either categories or identity predicts children's altruistic behavior.

We begin by investigating the patterns of ethnic self-identification among our study participants. We measure the strength of children's self-identification with ethnic categories by eliciting their "perceived similarity to self" in response to photographs of children from different ethnicities. Our procedures give participants from the majority White group and the two ethnic minority groups (East and South Asians) the opportunity to identify with any or all of these ethnicities. Previous research suggests that the processes shaping the social identities of children may differ for children from majority versus minority groups. If, as proposed by social identity theory, individuals define their in-group such that it will contribute to a positive sense of self, minority children might expand their in-group to include higher status or majority ethnic categories (Blanz, Mummendey, Mielke, \& Klink, 1998; Hornsey \& Hogg, 2000). This conjecture is supported by evidence showing that participants are more likely to endorse and identify with a larger superordinate category when the status of that category is experimentally manipulated to be higher (Hornsey \& Hogg, 2002). We use our photo selection strategy to measure children's evaluations of each of these ethnic categories with respect to sociability and competence, and interpret these as measures of status in order to inform our understanding of the patterns of ethnic identification that we observe.

We then examine participants' allocations in a dictator game in which proposers make offers to three hypothetical others, represented by photos of same-gender children from each of the three ethnic categories. We consider the observed patterns of sharing in the context of participant's identification with these groups, and directly test the hypothesis that the strength of ethnic identification is associated with children's altruistic choices.

\section{Sample characteristics}

Our study participants were recruited from public school students enrolled in Kindergarten, Grade 1 and Grade 2, in Vancouver, Canada, a highly diverse population in which Whites are the dominant group. By focusing on school-age children, we 
Table 1

\begin{tabular}{llll}
\multicolumn{2}{l}{ Frequencies of sample characteristics, by participant ethnicity. } \\
\hline & Whites & East Asian & South Asian \\
\hline Age & & & \\
Five & 0.30 & 0.32 & .26 \\
Six & 0.49 & 0.43 & .36 \\
Seven & 0.20 & 0.21 & .33 \\
Eight & 0.01 & 0.05 & .05 \\
Female & 0.52 & 0.42 & .49 \\
ESL & 0.04 & 0.62 & .56 \\
Observations & 214 & 186 & 39 \\
\hline
\end{tabular}

are able to gain access to a large number of subjects in a consistent institutional environment. We focus on the early grades in order to gain insight into the developmental processes shaping social identity, ethnic stereotypes and altruism among young children.

We restrict our attention to children whose own ethnicity is represented among our target photos, that is, those who were identified by their teachers as belonging to a single ethnic group that is White, East Asian (Chinese, Korean or Japanese) or South Asian (Indian, Pakistani or Sri Lankan). Of these, 214 participants are White, 186 are East Asian and only 39 are South Asian. Among the East Asian participants, over 94\% were characterized by their teachers as Chinese, and the remainder as Japanese or Korean. The children in our estimation sample are drawn from 30 different Vancouver public schools. Parents of $72 \%$ of the children in participating classrooms gave consent for their child to take part in the study. With absences, the overall participation rate was $69 \%$.

Table 1 reports sample characteristics by participant ethnicity. The age distributions of the White and East Asian participants are quite similar; just under one-third of subjects are 5 years old, slightly less than half are 6 years old, about one-fifth are 7 years old, and a small fraction of participants are 8 years old. The South Asian participants tend to be slightly older. The response rate among East Asian females was lower than other groups; as a result the proportion of East Asian subjects who are female is only $42 \%$, compared to $52 \%$ of Whites. Over $62 \%$ of East Asians and $56 \%$ of South Asians were enrolled in English as a Second Language (ESL) programs, while only $4 \%$ of Whites were in ESL.

\section{Experimental procedures}

Teams of 3-4 testers were formed to work with children from each participating classroom. Each child was individually engaged in two sets of activities, which were introduced in random order as a series of games. The "sorting task" was designed to elicit participants" beliefs about different ethnic groups, and the "sharing task" or dictator game was designed to assess ethnic discrimination in children's altruistic behavior.

\subsection{The sorting task}

At the beginning of each session, the researcher took a digital photograph of the child, which was immediately printed. This photo was added to a testing pack consisting of four sets of three matched photos of children who were unknown to participants (that were not used in the dictator game), two for each gender. ${ }^{1}$ All 13 photos ( 2 males and 2 females from each of the ethnic groups, plus the child's own photograph) were shuffled and placed randomly in front of the child. The researcher asked the child to sort the 13 photographs using the following standard request format: "Pick all the children who are _ and, leave all the children who are not _ on the table." The child was informed that she/he was free to pick all, some or none of the 13 photographs. The photographs were shuffled and were placed randomly in front of the child before each question. In order to make sure that the child understood the nature of the task, in the first two trials, the child was asked to pick the "girls" and the "boys".

The sorting task was used to assess children's evaluations of others' competence and sociability, and their perceived similarity to others. The sociability trials required children to pick those who are nice to other children, who are happy, who have lots of friends, and who are helpful. The competence trials require children to pick those who are smart, who work hard, who read well, and who like school. The extent to which children identify with targets was assessed by asking them to "pick all the children who are like you." For each trial, children can choose between 0 and 4 targets from each of the three ethnic groups (excluding the childs own photo). This approach allows children to associate themselves with multiple ethnic categories, and to indicate the strength of their identification by selecting more or fewer photos.

\footnotetext{
${ }^{1}$ Approximately 350 head-and-shoulder photographs of 5- to 7-year old White, East Asian and South Asian children were pretested for clarity of the photograph, physical attractiveness, facial expression, gender, age, and ethnicity of the child. Nine adults from four different ethnic backgrounds rated the photographs on each of these dimensions on a seven-point Likert scale. First, only photographs that received unanimous agreement on ethnicity and gender of the child were retained. These photographs were then matched on the remaining criteria (age, physical attractiveness, facial expression, and the clarity of the photograph) to create sets of three same gender children one from each of the three ethnic groups. The procedure and materials for this task were adopted from Wright and Taylor (1995).
} 


\subsection{The dictator game}

Like Eckel and Petrie (2011), we represent receivers in our game using photos. Boys give to boys only; girls give to girls only. All participants play the game three times, each time with 12 stickers that they can divide four ways (self, White, East Asian, South Asian). By allowing children to view the three target photos simultaneously, our intention is to increase the salience of phenotypic differences among them. At the same time, however, this approach may increase the salience of fairness. $^{2}$

\subsection{Supplemental data}

After testing was complete, each classroom teacher was asked to fill out an information sheet that included questions about each participant's characteristics, including their ethnicity, gender, home language, and English language proficiency, and to provide aggregate information about the overall composition of the classroom (including children who did not participate in the study). Teachers' assessments of children's ethnicity may be informed by their knowledge of the child's phenotype, the parents' phenotype, and the family's home language and culture. Finally, we collected participants' residential postal codes on the Parent Permission Form required for all participants, and linked these postal codes to 2001 Census information about the characteristics of the population residing in the same Dissemination Area (DA). DAs are geographic areas designated for the collection of Census data, and are composed of one or more neighboring blocks with a population of 400700 persons. Details of the linking of postal codes to DAs are provided in the data Appendix.

\section{Ethnic identity}

As described earlier, both theory and previous evidence suggest that children from dominant majority groups tend to identify positively with their own ethnic group, while minority children may also identify with higher status ethnic majority categories. We begin by investigating the status of the three target ethnic groups among our participants, measured by their evaluations of the sociability and competence of each target ethnicity. We then evaluate the tendency of children in each ethnic category to identify with the target ethnicities according to our measure of perceived similarity.

\subsection{Results}

The first column of Table 2 shows the mean number of photos selected by White, East Asian and South Asian participants respectively from each target group in response to the sociability, competence and perceived similarity items. Out of a maximum of four photos per target ethnicity (two boys and two girls), participants selected between 2.3 and 2.9 photos on average in response to the items in the sociability and competence scales. The next three columns show the two-way differences (between target ethnicities) in the average number of photos that participants choose, for each group of participants. The final column reports the frequency with which participants chose their own photos.

The first panel shows results for evaluations of sociability and the second panel for competence. All three groups of participants evaluated the White targets as being both the most social and the most competent, followed by the East Asian targets and finally the South Asian targets. While their ranking of target ethnicities was the same as the other two groups, the magnitude of the distinctions between them was smallest among South Asian participants. However, none of these distinctions is statistically significant.

The third panel of Table 2 shows that, on average, White and East Asian participants selected 1.2 out of 4 photos from each target ethnicity as being "like them", and South Asian participants chose slightly more (1.4). These numbers are substantially lower than the average number of photos selected in response to the sociability and competence items, reflecting relatively low selection rates of opposite gender photos in response to the perceived similarity item. Overall, White participants selected White photos about 50\% more often than East Asian photos (.60/1.2), and about 70\% more often than South Asian photos (.89/1.2), and these differences are statistically significant. East Asian participants selected East Asian photos about 45\% more often than South Asian photos (.56/1.2); they selected East Asian photos only $16 \%$ more often than White photos (-.20/1.2), and this latter difference is not statistically significant. South Asian participants selected about $39 \%$ more South Asian photos than White photos (-.55/1.4), and about 36\% more South Asian photos than East Asian photos (-.50/1.4). Although the magnitudes of these differences are substantial, they are not estimated very precisely due to the small number of South Asian participants.

\subsection{Discussion}

Research involving children from dominant majority groups has shown that from the age of three, they evaluate both their own gender and ethnic group more positively than others, like them more and feel more similar to them (e.g. Aboud,

\footnotetext{
${ }^{2}$ We engaged a smaller number of subjects in a "sequential" version of our procedure, in which children played a series of two-person games against the targets. This method produced very noisy responses.
} 
Table 2

Evaluations of sociability and competence and perceived similarity to ethnic phenotypes, by participant ethnicity.

\begin{tabular}{|c|c|c|c|c|c|}
\hline \multirow[t]{2}{*}{ Photos chosen by } & \multirow{2}{*}{$\begin{array}{l}\text { Mean chosen per target ethnicity, excluding self } \\
\text { Mean (st. dev.) }\end{array}$} & \multicolumn{3}{|c|}{ Difference in means across target ethnicities, excluding self $^{\mathrm{b}}$} & \multirow[t]{2}{*}{$N$} \\
\hline & & White-East Asian & White-South Asian & East-South Asian & \\
\hline \multicolumn{6}{|l|}{ Sociability } \\
\hline Whites & $2.94(.89)$ & 0.22 & 0.44 & 0.22 & 281 \\
\hline East Asians & $2.31(1.07)$ & 0.20 & 0.42 & 0.22 & 253 \\
\hline South Asians & $2.64(1.11)$ & 0.15 & 0.31 & 0.16 & 60 \\
\hline \multicolumn{6}{|l|}{ Competence } \\
\hline Whites & $2.59(1.04)$ & 0.20 & 0.29 & 0.10 & 280 \\
\hline East Asians & $2.56(1.00)$ & 0.14 & 0.45 & 0.32 & 255 \\
\hline South Asians & $2.39(1.11)$ & 0.06 & 0.18 & 0.12 & 62 \\
\hline \multicolumn{6}{|l|}{ Perceived similarity } \\
\hline Whites & $1.21(1.25)$ & $0.60^{* * *}$ & $0.89^{* * *}$ & $0.28^{*}$ & 280 \\
\hline East Asians & $1.21(1.25)$ & -0.20 & $0.36^{* * *}$ & $0.56^{* * *}$ & 253 \\
\hline South Asians & $1.43(1.30)$ & 0.04 & $-0.55^{*}$ & -0.50 & 60 \\
\hline
\end{tabular}

${ }^{* *} p<0.05$.

* $p<0.1$.

$p<0.01$.

a Range $=0-4$ (two photos of boys and two photos of girls, from a given target ethnicity).

b Wilcoxon Rank Sum tests for differences in means.

1988; Martin, Ruble, \& Szkrybalo, 2002; Nessdale, Maass, Griffiths, \& Durkin, 2003). Our results for White participants are weakly consistent with this evidence. White participants exhibit stereotypic beliefs and rank the three ethnic categories from Whites (highest) to South Asians (lowest) according to both sociability and competence, although these distinctions are not statistically significant. Their patterns of perceived similarity reveal a clear sense of identification with the White target, and relatively weak identification with the targets from the lower status minority ethnic groups. Whites perceive themselves to be least similar to the South Asian target, which they evaluate least favorably.

East Asian participants share Whites' rankings of the three ethnic groups according to sociability, situating their own group between Whites and South Asians. Again, however, there is no statistically significant difference between their evaluations of the three targets. This result differs from the findings of previous research that East Asian children aged five to seven tend to identify East Asian children rather than White children as being good at math Ambady, Shih, Kim, and Pittinsky (2001). We speculate that our results may differ from these because our competence items are different. "Reads well" may be a trait associated with White children, of whom a much larger proportion are native English speakers. Reading and oral skills may be the most visible markers of "being smart" for children in this age group, if they are the most salient academic competencies sought by teachers in the early grades. None of our competency items specifically refers to quantitative skills.

Unlike Whites, East Asians do not reveal a clear sense of identification with their own ethnic category. Instead, they appear to associate themselves with a super-ordinate ethnic group that includes the White as well as the East Asian ethnicity, but excludes South Asians. These results are consistent with previous evidence that minority groups may expand their ingroup to include higher status or majority ethnic categories (Blanz et al., 1998; Hornsey \& Hogg, 2000) and that minority children express preferences for contact with the majority outgroup (e.g. Clark \& Clark, 1939; Clark \& Clark, 1947; Clark \& Cook, 1988; Corenblum \& Annis, 1993; Katz \& Braly, 1933, 1996; Aboud \& Doyle, 1996).

Although the point estimates indicate the same ranking of Whites (highest), East Asians and South Asians (lowest), South Asians perceive smaller differences in the sociability and especially in the competence of the three target ethnicities. This pattern of results provides weak evidence that South Asians may be evaluating their own group relatively favorably, compared to prevailing stereotypes. Unlike the East Asian minority group, however, South Asians do not associate themselves with a super-ordinate ethnic group that includes higher status categories. Instead, like Whites, they have a clear tendency to identify more strongly with their own ethnic category than with the other two.

\section{Altruistic behavior}

Table 3 characterizes the general patterns of sharing behavior in the data. Overall, participants share on average 13.6/36 stickers or 38\% of their endowment. South Asian children share fewer stickers overall (11.7) compared to Whites (13.8) and East Asians (13.7). These results are similar to Gummerum et al.'s (2008) results for German children, who allocated on average between $35 \%$ and $40 \%$ of their endowment to anonymous others in a dictator game. As those authors note, these allocations are greater than both the $20 \%$ that is typically offered by adults (e.g. Camerer, 2003), and the offers made by young children in two US studies (Bettinger \& Slonim, 2006; Harbaugh \& Krause, 2000). Like previous authors, (e.g. Benenson, Pascoe, \& Radmore, 2007; Bettinger \& Slonim, 2006; Fehr et al., 2008; Harbaugh, Krause, \& Liday, Unpublished manuscript), we find that children share more as they grow older; the average number of stickers shared by 7-year olds in our sample (15.9) is substantially greater than the average number shared by 5-year olds (12.7). Our results also confirm 
Table 3

Characteristics of sharing behavior, by age and gender.

\begin{tabular}{lll}
\hline & Average number shared & Frequency not discriminating \\
\hline All & 13.6 & .50 \\
White & 13.8 & .55 \\
East Asian & 13.7 & .45 \\
South Asian & 11.7 & .40 \\
Age & & \\
$\quad$ Five & 12.4 & .46 \\
$\quad$ Six & 13.3 & .50 \\
$\quad$ Seven & 15.2 & .50 \\
Female & 14.8 & .54 \\
Male & 12.8 & .42 \\
\hline
\end{tabular}

a Proportion of participants who allocate the same number of stickers to each of the three targets.

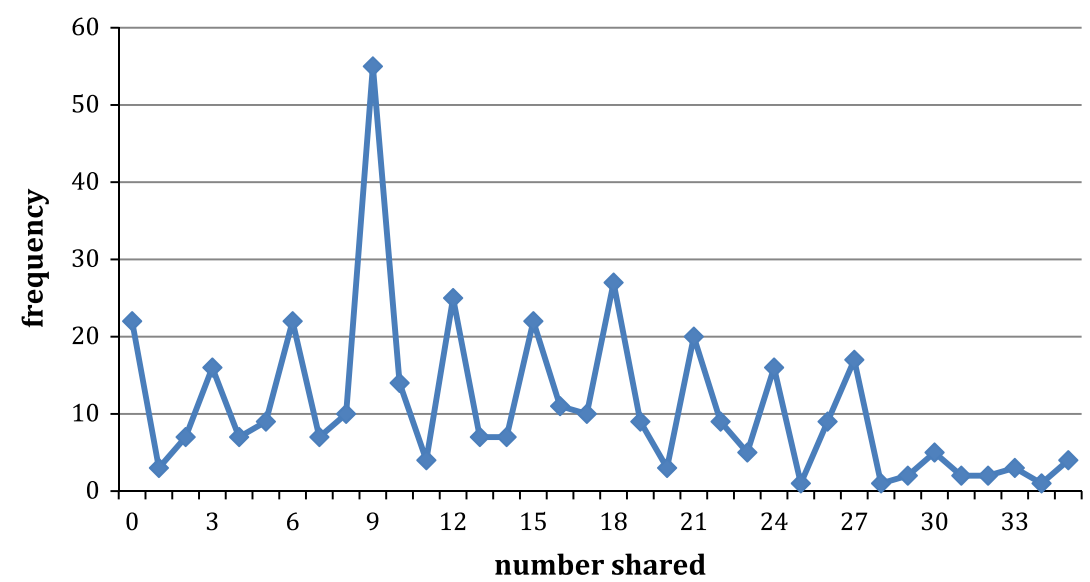

Fig. 1. Frequencies of total number of stickers shared. Note: Total number of stickers shared by participant $i$ is the sum across all three trials $t$, and all three target photos $j=\mathrm{W}, \mathrm{EA}, \mathrm{SA}: q_{i} \sum_{j} \sum_{t=1}^{3} q_{i j t}$.

previous results that girls (14.8) share more than boys (12.8) when playing the dictator game (Gummerum et al., 2009; Harbaugh et al., Unpublished manuscript).

The frequency distribution of the number of stickers shared by each child, presented in Fig. 1, shows pronounced spikes at multiples of three. The modal response was nine stickers, chosen by $14.0 \%$ of subjects. The second highest frequency was eighteen stickers, chosen by $6.9 \%$ of participants. These spikes are suggestive of non-discriminatory sharing, i.e. sharing the same number of stickers with each of the three recipients. The second column of Table 3 shows that $50 \%$ of participants chose a non-discriminatory allocation (including $5.2 \%$ of participants who shared zero stickers). Non-discriminatory sharing may be chosen frequently because it provides a cognitively undemanding rule of thumb (Messick, 1993), or because it reflects children's developing egalitarianism or norms of fairness that may be reinforced in school environments (Fehr et al., 2008). White participants were substantially more likely (55\%) than East Asian (45\%) and South Asian (40\%) participants to choose a non-discriminatory allocation, and girls were more likely (54\%) than boys (42\%) to do so. Non-discriminatory behavior is slightly less frequent among 5-year olds (46\%) than among 6- and 7-year olds (50\%).

Table 4 presents more detailed information about sharing behavior by participants from different ethnic categories. Columns 1-3 show that, on average, White participants shared slightly more stickers with the recipient from their own ethnic category than with the other two; East Asians participants shared slightly fewer with their own category than with the other two; and South Asian participant shared slightly fewer with the East Asian recipient than with the other two. Columns 4-6 show results for the sub-sample of participants who did not share the same number of stickers with each of the three recipients. Among participants who discriminate, these patterns of discriminatory sharing are more pronounced.

We next examine the relationship between ethnic categories, ethnic identity and altruism in the dictator game.

\subsection{Empirical framework}

In each trial $t$, participants choose to allocate an endowment of $E$ stickers between themselves and one photo each of same-gender White, East Asian and South Asian children (three photos in total). We aggregate each participant's allocation 
Table 4

Average number of stickers shared.

\begin{tabular}{|c|c|c|c|c|c|c|}
\hline \multirow[t]{3}{*}{ Shared by } & \multicolumn{3}{|c|}{ All participants } & \multicolumn{3}{|c|}{ Participants who discriminate ${ }^{\mathrm{a}}$ among targets } \\
\hline & \multicolumn{6}{|c|}{ Shared with } \\
\hline & White & East Asian & South Asian & White & East Asian & South Asian \\
\hline Whites & 4.8 & 4.5 & 4.5 & 5.3 & 4.7 & 4.8 \\
\hline East Asians & 4.7 & 4.5 & 4.6 & 5.1 & 4.8 & 5.0 \\
\hline South Asians & 4.1 & 3.9 & 4.1 & 3.7 & 3.1 & 3.9 \\
\hline
\end{tabular}

a Participants who do not allocate the same number of stickers to each of the three targets.

to recipient photo $j=\mathrm{w}$, ea, sa (White, East Asian and South Asian respectively) across all three trials to generate each participant's overall allocation to each recipient ethnicity $\left(q_{i j}=\sum_{t=1}^{3} q_{i j t}\right)$.

Suppose that participant $i$ has preferences over this allocation that are represented by the following utility function:

$$
U_{i}=U\left(q_{i 0}, q_{i W}, q_{i E A}, q_{i S A}, x_{i} ; \theta\right)
$$

where $q_{i 0}$ is the number of stickers kept by the subject for themselves, $q_{i j}$ is the number of stickers allocated to recipient photo $j, x_{i}$ is a vector of individual characteristics that influence preferences (including ethnicity), and $\theta$ is a parameter vector. Subjects choose the allocation $\left\{q_{i 0}, q_{i w}, q_{i B A}, q_{i S A}\right\}$ to maximize this utility function, subject to the endowment constraint. The allocations that maximize utility can be written:

$$
\begin{aligned}
& q_{i j}^{*}=f_{j}\left(x_{i} ; \theta\right) \\
& q_{i 0}^{*}=E-\left(q_{i W}^{*}+q_{i E A}^{*}+q_{i S A}^{*}\right)
\end{aligned}
$$

We are interested in the extent to which participants' sharing allocations are systematically biased towards any ethnic categories, and particularly whether they favor their own group. We investigate two different ways of characterizing ethnic bias. In the first case, we specify our estimating equation in order to focus on the relative number of stickers that participants share across recipient photos, rather than the absolute number of stickers they choose to share with each recipient. Specifically, our dependent variable is an indicator for whether more than one-third of the total number of stickers shared by participant $i$ were allocated to ethnic category $j$.

$$
y_{i j}=D:\left[\left(q_{i j}-\frac{1}{3} \sum_{j} q_{i j}\right)>0\right]
$$

where $D:[\cdot]$ is an operator that assigns the value one when the condition inside the square brackets is satisfied, and zero otherwise. This way of defining favoritism allows participants to favor zero, one or two recipients. For example, a participant who allocates nine stickers in total could show no favoritism by choosing to allocate three stickers to each recipient (3-3-3) or by sharing no stickers at all (0-0-0), favor one of the recipients at the expense of one or both of the others (e.g. 5-3-1 or 52-2), or favor two recipients at the expense of a third (e.g. 5-4-0 or 4-4-1). This feature of our definition of favoritism allows for the important possibility that participants whose ethnic identities encompass two ethnic categories may favor both categories.

Our baseline model for each of these relative allocation decisions as follows:

$$
\begin{aligned}
& y_{i j}=f\left(X_{i j}^{\prime} \beta+\mu_{i j}\right) \\
& X_{i j}^{\prime} \beta=\left(\beta_{0}+\beta_{1} \operatorname{TgtOwn}_{i j}\right)+\left(\beta_{2}+\beta_{3} \text { TgtOwn }_{i j}\right)^{*} \operatorname{partEA}_{i}+\left(\beta_{4}+\beta_{5} \operatorname{TgtOwn}_{i j}\right)^{*} \operatorname{partSA}_{i}
\end{aligned}
$$

where $\operatorname{TgtOWn}_{i j}$ indicates that the recipient is from the same ethnic group as the participant, $\operatorname{partEA}_{i}$ and $\operatorname{partSA}_{i}$ indicate that the participant is East Asian or South Asian respectively, and $\beta_{0}-\beta_{5}$ are parameters to be estimated. We assume the following specification for the stochastic error term $\mu_{i j}$ :

$$
\mu_{i j}=\delta_{i}+\varepsilon_{i j}
$$

Here $\delta_{i}$ is a random person effect and $\varepsilon_{i j}$ is an idiosyncratic error term. We estimate Eq. (4) using a random effects (also known as a mixed effects) probit model.

The probit model affords a direct test of the hypothesis that participants favor their in-group. However, it does not allow us to assess the intensity of any in-group bias. In order to do so, we estimate an alternative model in which the dependent variable is the number of stickers shared with each recipient:

$$
q_{i j}=g\left(X_{i j}^{\prime} \Theta+\phi_{i j}\right)
$$

where $X_{i j}^{\prime} \Theta$ takes the same form as $X_{i j}^{\prime} \beta$ in (5), and the stochastic error term $\phi_{i j}$ includes both a random person effect and an idiosyncratic error term. We estimate Eq. (6) using a negative binomial model to accommodate the count nature of the dependent variable, and cluster the standard errors at the participant level. 
Table 5

Results, sharing in the dictator game ${ }^{a}$.

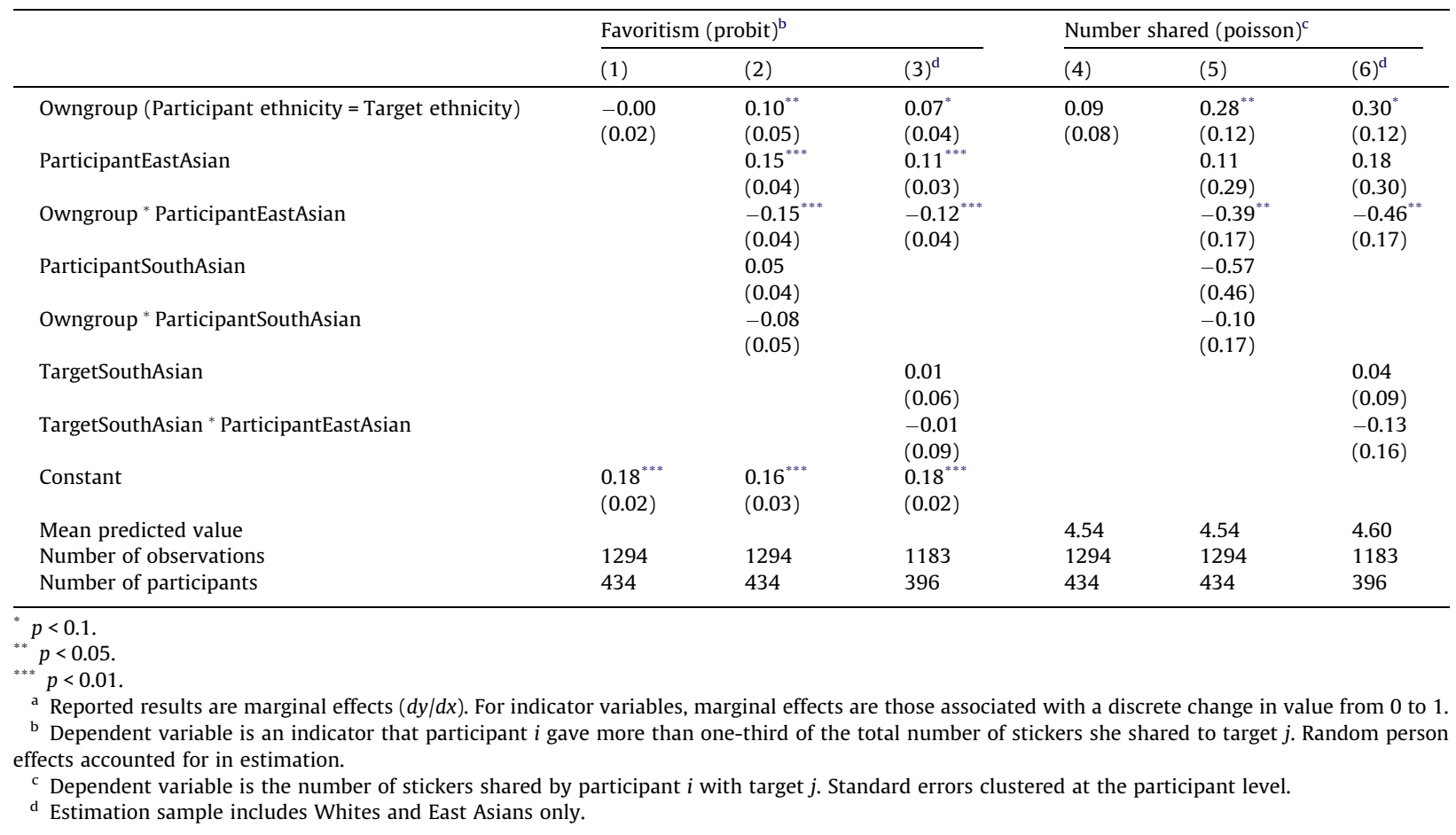

\subsection{Results}

\subsubsection{Baseline results}

The unit of observation is a participant/recipient pair, so the estimation sample consists of three observations for each participant, each corresponding to a different recipient. All recipients are the same gender as the participant. We begin by reporting our results from the probit model in which the dependent variable is an indicator for whether the participant favored (gave more than one-third of the total number of stickers they shared to) a given recipient. The dependent variable takes on the value zero in all three observations corresponding to a given participant if the child shares equally across all three recipients. If the child does not share equally across all three recipients, the dependent variable may take on the value in at most two cases, since the proportion of stickers shared with each recipient must sum to one within each set of three child/recipient observations.

The estimated marginal effects reported in the first column of Table 5 correspond to a specification that includes only an indicator for whether the child belongs to the same ethnic category as the recipient photo. Participants give a recipient more than a third of the total number of stickers they share in about $18 \%$ of cases. On average, however, they are no more likely to favor the recipient from their own ethnic category than to favor a recipient from one of the other ethnic categories.

The specification in the second column relaxes the constraint that participants from different ethnic categories behave similarly. In this specification, the omitted group is White children giving to Whites, and the tendency to favoritism is constrained to be the same across outgroups (e.g. Whites equally likely to favor East Asians and South Asians). The proportion of children who favor their own category is $26 \%$ among Whites (constant + owngroup), $26 \%$ among East Asians (constant + participantEA + owngroup + owngroup * participantEA), and 23\% among South Asians (constant + participantSA + owngroup + participantSA). The difference in the behavior of South Asians participants and the other two groups is not statistically significant.

Only $16 \%$ of White children (constant) and 21\% (constant + participantSA) of South Asian children favor each of the other groups, compared to $31 \%$ (constant + participantEA) of East Asians. We cannot reject the null hypothesis that the behavior of Whites and South Asians towards out-group categories is the same. However, the behavior of East Asian children towards out-group categories is statistically significantly different from the behavior of both Whites and South Asians.

Having established that there are significant differences between the behavior of Whites and South Asians on one hand and East Asians on the other, we now seek to characterize the behavior of each group in terms of in-group bias. The number of Whites who favor the White recipient is 10 percentage points larger than the number of Whites who favor each of the other recipients (owngroup), and this difference is statistically significant ( $p=.06$ ). In contrast, the number of East Asian participants who favor the East Asian recipient is 5 percentage points lower than the number who favor each of the other two 
Table 6

Results, sharing in the dictator game, with demographic variables, White and East Asian participants only ${ }^{\mathrm{a}}$.

\begin{tabular}{|c|c|c|c|c|c|c|}
\hline & \multicolumn{3}{|c|}{ Favoritism (probit) ${ }^{\mathrm{b}}$} & \multicolumn{3}{|c|}{ Number shared (poisson) ${ }^{\mathrm{c}}$} \\
\hline & (1) & $(2)$ & (3) & $(4)$ & (5) & (6) \\
\hline Owngroup & $\begin{array}{l}0.07^{*} \\
(0.04)\end{array}$ & $\begin{array}{l}0.08 \\
(0.05)\end{array}$ & $\begin{array}{l}0.07 \\
(0.07)\end{array}$ & $\begin{array}{l}0.28^{* * *} \\
(0.12)\end{array}$ & $\begin{array}{l}0.35 \\
(0.25)\end{array}$ & $\begin{array}{l}0.55^{*} \\
(0.29)\end{array}$ \\
\hline ParticipantEastAsian & $\begin{array}{l}0.11^{* * *} \\
(0.03)\end{array}$ & $\begin{array}{l}0.12^{* * *} \\
(0.04)\end{array}$ & $\begin{array}{l}0.09 \\
(0.06)\end{array}$ & $\begin{array}{l}0.11 \\
(0.29)\end{array}$ & $\begin{array}{l}0.45 \\
(0.43)\end{array}$ & $\begin{array}{l}0.12 \\
(0.58)\end{array}$ \\
\hline Owngroup * ParticipantEastAsian & $\begin{array}{l}-0.13^{* * *} \\
(0.04)\end{array}$ & $\begin{array}{l}-0.17^{* * *} \\
(0.04)\end{array}$ & $\begin{array}{l}-0.19^{* * *} \\
(0.05)\end{array}$ & $\begin{array}{l}-0.40^{* *} \\
(0.17)\end{array}$ & $\begin{array}{l}-0.68^{* * *} \\
(0.23)\end{array}$ & $\begin{array}{l}-0.92^{* * *} \\
(0.30)\end{array}$ \\
\hline Female & & $\begin{array}{l}-0.06 \\
(0.04)\end{array}$ & $\begin{array}{l}-0.06 \\
(0.04)\end{array}$ & & $\begin{array}{l}0.70^{*} \\
(0.39)\end{array}$ & $\begin{array}{l}0.73^{*} \\
(0.39)\end{array}$ \\
\hline Owngroup * Female & & $\begin{array}{l}-0.02 \\
(0.07)\end{array}$ & $\begin{array}{l}-0.02 \\
(0.07)\end{array}$ & & $\begin{array}{l}-0.13 \\
(0.24)\end{array}$ & $\begin{array}{l}-0.15 \\
(0.24)\end{array}$ \\
\hline Female * ParticipantEastAsian & & $\begin{array}{c}-0.04 \\
(0.06)\end{array}$ & $\begin{array}{l}-0.04 \\
(0.06)\end{array}$ & & $\begin{array}{l}-0.59 \\
(0.54)\end{array}$ & $\begin{array}{r}-0.72 \\
(0.53)\end{array}$ \\
\hline Owngroup ${ }^{*}$ Female * ParticipantEastAsian & & $\begin{array}{l}0.19 \\
(0.14)\end{array}$ & $\begin{array}{l}0.18 \\
(0.14)\end{array}$ & & $\begin{array}{l}0.72^{*} \\
(0.43)\end{array}$ & $\begin{array}{l}0.77^{*} \\
(0.45)\end{array}$ \\
\hline Age & & & $\begin{array}{l}-0.00 \\
(0.03)\end{array}$ & & & $\begin{array}{l}0.36 \\
(0.25)\end{array}$ \\
\hline Owngroup * Age & & & $\begin{array}{l}0.01 \\
(0.05)\end{array}$ & & & $\begin{array}{l}-0.19 \\
(0.13)\end{array}$ \\
\hline Age * ParticipantEastAsian & & & $\begin{array}{l}0.03 \\
(0.04)\end{array}$ & & & $\begin{array}{l}0.33 \\
(0.35)\end{array}$ \\
\hline Owngroup * Age * ParticipantEastAsian & & & $\begin{array}{l}0.04 \\
(0.07)\end{array}$ & & & $\begin{array}{l}0.26 \\
(0.21)\end{array}$ \\
\hline Constant & $\begin{array}{l}0.18^{* * *} \\
(0.02)\end{array}$ & $\begin{array}{l}0.21^{* * *} \\
(0.03)\end{array}$ & $\begin{array}{l}0.21^{* * *} \\
(0.03)\end{array}$ & & & \\
\hline Mean predicted value & & & & 4.59 & 4.59 & 4.57 \\
\hline Number of observations & 1183 & 1183 & 1183 & 1183 & 1183 & 1183 \\
\hline Number of participants & 396 & 396 & 396 & 396 & 396 & 396 \\
\hline
\end{tabular}

* $p<0.1$.

** $p<0.05$.

**** $p<0.01$.

a Reported results are marginal effects $(d y / d x)$. For indicator variables, marginal effects are those associated with a discrete change in value from 0 to 1.

b Dependent variable is an indicator that participant $i$ gave more than one-third of the total number of stickers she shared to target $j$. Random person effects accounted for in estimation.

c Dependent variable is the number of stickers shared by participant $i$ with target $j$. Standard errors clustered at the participant level.

(owngroup + owngroup * participantEA), and this difference is also statistically significant $(p=.03)$. Note again that the difference between the behavior of East Asian children and White children towards their own group relative to other groups comes primarily from differences in their behavior towards the other groups; their behavior towards their own group does not differ in any significant way. While the absolute magnitudes of these differences in favoritism are fairly small, they indicate clearly that the ethnicity of the recipient is salient to White and East Asian children's sharing behavior in the classroom environment.

According to the point estimates, the number of South Asians who favor the South Asian recipient is 8 percentage points larger than the number of South Asians who favor each of the other two (owngroup + owngroup * participantSA). The estimate of in-group bias is very imprecise, however, and is not statistically significant $(p=.51)$. Given the small South Asian sample size and the resulting problem with precision, we restrict our attention to in-group bias among Whites and East Asians and exclude South Asians from our estimation samples in the remaining regressions.

The specification reported in the third column of Table 5 excludes South Asians from the estimation sample and includes a variable indicating that the recipient is South Asian and its interaction with an indicator that the participant is East Asian. Its' purpose is to provide a basis for testing the constraint that White and East Asian children do not distinguish between outgroups. The results show that White children favor the East Asian (constant) and South Asian recipients (constant + targetSA) with equal frequency, and East Asian children favor the White (constant + participantEA) and South Asian recipients (constant + participantEA + targetSA + targetSA * participantEA) with equal frequency. In other words, neither ethnic group distinguishes between the two out-group categories.

We next report results for the model where the dependent variable is the number of stickers shared with each recipient. This alternative specification frames the central hypothesis in terms of levels, rather than indicators of favoritism, in order to provide a sense of the intensity of bias. The estimated marginal effects in column 5 show that White subjects share slightly less than one-third of a sticker more on average with the White target than with either of the other two recipients (owngroup). However, East Asian participants show no in-group bias; if anything, they share fewer stickers with their own group with other groups (owngroup + owngroupEA). This difference in patterns of in-group bias between Whites and East Asians is statistically significant. As before, the relevant point estimates indicate that South Asians may show somewhat less in-group 
Table 7

Results, sharing in the dictator game with tester ethnicity and neighborhood income, White and East Asian participants only ${ }^{\mathrm{a}}$.

\begin{tabular}{|c|c|c|c|c|c|c|}
\hline & \multicolumn{3}{|c|}{ Favoritism (probit) $^{b}$} & \multicolumn{3}{|c|}{ Number shared (negative binomial) ${ }^{\mathrm{c}}$} \\
\hline & $(1)$ & $(2)$ & $(3)$ & $(4)$ & $(5)$ & $(6)$ \\
\hline Owngroup & $\begin{array}{l}0.07^{*} \\
(0.04)\end{array}$ & $\begin{array}{l}0.08 \\
(0.05)\end{array}$ & $\begin{array}{l}0.09^{* *} \\
(0.05)\end{array}$ & $\begin{array}{l}0.28^{* *} \\
(0.12)\end{array}$ & $\begin{array}{l}0.25 \\
(0.16)\end{array}$ & $\begin{array}{l}0.30^{*} \\
(0.16)\end{array}$ \\
\hline ParticipantEastAsian & $\begin{array}{l}0.11^{* * * *} \\
(0.03)\end{array}$ & $\begin{array}{l}0.10^{* *} \\
(0.04)\end{array}$ & $\begin{array}{l}0.10^{* *} \\
(0.05)\end{array}$ & $\begin{array}{l}0.11 \\
(0.29)\end{array}$ & $\begin{array}{l}0.35^{* *} \\
(0.15)\end{array}$ & $\begin{array}{l}0.44 \\
(0.47)\end{array}$ \\
\hline Owngroup * ParticipantEastAsian & $\begin{array}{l}-0.13^{* * *} \\
(0.04)\end{array}$ & $\begin{array}{l}-0.12^{* *} \\
(0.05)\end{array}$ & $\begin{array}{l}-0.19^{* * *} \\
(0.04)\end{array}$ & $\begin{array}{l}-0.40^{* *} \\
(0.17)\end{array}$ & $\begin{array}{l}-0.47^{* *} \\
(0.24)\end{array}$ & $\begin{array}{l}-0.54^{* * *} \\
(0.20)\end{array}$ \\
\hline TesterNonwhite & & $\begin{array}{l}0.05 \\
(0.05)\end{array}$ & & & $\begin{array}{l}.17 \\
(0.16)\end{array}$ & \\
\hline TesterNonwhite ${ }^{*}$ ParticipantEastAsian & & $\begin{array}{l}0.02 \\
(0.07)\end{array}$ & & & $\begin{array}{l}.07 \\
(0.22)\end{array}$ & \\
\hline Owngroup * TesterNonwhite & & $\begin{array}{l}-0.02 \\
(0.07)\end{array}$ & & & $\begin{array}{l}-0.06 \\
(0.25)\end{array}$ & \\
\hline Owngroup * TesterNonwhite * ParticipantEastAsian & & $\begin{array}{c}-0.02 \\
(0.10)\end{array}$ & & & $\begin{array}{l}-0.08 \\
(0.36)\end{array}$ & \\
\hline LowIncome & & & $\begin{array}{l}-0.01 \\
(0.05)\end{array}$ & & & $\begin{array}{l}0.27 \\
(0.44)\end{array}$ \\
\hline LowIncome * ParticipantEastAsian & & & $\begin{array}{l}0.01 \\
(0.07)\end{array}$ & & & $\begin{array}{l}-0.41 \\
(0.61)\end{array}$ \\
\hline Owngroup * Lowincome & & & $\begin{array}{l}-0.05 \\
(0.07)\end{array}$ & & & $\begin{array}{l}0.05 \\
(0.26)\end{array}$ \\
\hline Owngroup * Lowincome * ParticipantEastAsian & & & $\begin{array}{l}0.20 \\
(0.15)\end{array}$ & & & $\begin{array}{l}0.18 \\
(0.37)\end{array}$ \\
\hline Constant & $\begin{array}{l}0.18^{* * *} \\
(0.02)\end{array}$ & $\begin{array}{l}0.16^{* * * *} \\
(0.03)\end{array}$ & $\begin{array}{l}0.19^{* * * *} \\
(0.03)\end{array}$ & & & \\
\hline Mean predicted value & & & & 4.59 & 4.59 & 4.63 \\
\hline Number of observations & 1183 & 1183 & 1114 & 1183 & 1183 & 1114 \\
\hline Number of participants & 396 & 396 & 373 & 396 & 396 & 373 \\
\hline
\end{tabular}

${ }^{*} p<0.1$.

** $p<0.05$.

*** $p<0.01$.

a Reported results are marginal effects $(d y / d x)$. For indicator variables, marginal effects are those associated with a discrete change in value from 0 to 1 .

b Dependent variable is an indicator that participant $i$ gave more than one-third of the total number of stickers she shared to target $j$. Random person effects accounted for in estimation.

c Dependent variable is the number of stickers shared by participant $i$ with target $j$. Standard errors clustered at the participant level.

bias than Whites in terms of the number of stickers shared (owngroup + owngroupSA), but this difference is not statistically significant. The results in column 6 provide no evidence that Whites and East Asians distinguish between the two out-groups when sharing stickers.

\subsubsection{Specifications with demographic interactions}

We next investigate whether differences in the gender and age distributions of White and East Asian participants may explain any of the observed differences between their sharing behavior. The specification reported in the second column of Table 6 includes an indicator that the participant is female, interacted with all the variables in our main specification (reproduced in column 1). In the third column, we add the participant's age in years, again interacted with all of the variables in our main specification. The inclusion of these variables does not alter the main results, although larger standard errors mean that the in-group bias effect among White is no longer statistically significant. The results reveal no statistically significant differences in in-group bias according to age or gender. We see weak (statistically insignificant) evidence that the absence of in-group bias among East Asians is driven primarily by the behavior of boys.

When we consider the intensity of in-group bias, measured in terms of the number of stickers shared, the differences by gender among East Asian children are marginally statistically significant. The results in column 6, which correspond to a specification that includes interactions for both age and gender, show that both White boys $(p=.05)$ and White girls $(p=.03)$ share more stickers with their own group than with other groups on average. East Asian boys show out-group bias; they share fewer stickers on average with their own group than with other groups $(p=.03)$. East Asian girls demonstrate no in-group or out-group bias with respect to the total number of stickers shared $(p=.76)$. The difference between White and East Asian boys in their behavior towards their own group is statistically significant $(p=.004)$, but the difference between White and East Asian girls is not $(p=.52)$.

\subsubsection{Robustness checks}

We next investigate the possibility that children's behavior may be influenced by the ethnicity of the tester who administered the experimental procedures. Over $58 \%$ of participants interacted with a White/European tester, $12 \%$ with an East 
Table 8

Census neighborhood characteristics, by participant ethnicity.

\begin{tabular}{lll}
\hline & White & East Asian \\
\hline \%Immigrants & 38.6 & 56.0 \\
\%Poverty & 15.2 & 23.0 \\
\%High school or less & 23.7 & 38.0 \\
Mean family income & 105128 & 78034 \\
Observations & 214 & 186 \\
\hline
\end{tabular}

Table 9

Results, sharing in the dictator game, with indicator of ethnic identification, White and East Asian participants ${ }^{\mathrm{a}}$.

\begin{tabular}{|c|c|c|c|c|c|c|}
\hline & \multicolumn{3}{|c|}{ Favoritism (probit) $^{\mathrm{b}}$} & \multicolumn{3}{|c|}{ Number shared (negative binomial) ${ }^{c}$} \\
\hline & $(1)$ & $(2)$ & (3) & $(4)$ & $(5)$ & (6) \\
\hline Identifies with target ethnicity & $\begin{array}{l}0.02 \\
(0.03)\end{array}$ & $\begin{array}{l}0.08^{*} \\
(0.04)\end{array}$ & & $\begin{array}{l}0.24^{* *} \\
(0.10)\end{array}$ & $\begin{array}{l}0.35^{* * *} \\
(0.13)\end{array}$ & \\
\hline ParticipantEastAsian & & $\begin{array}{l}0.10^{* * *} \\
(0.03)\end{array}$ & $\begin{array}{l}0.11^{* * *} \\
(0.03)\end{array}$ & & $\begin{array}{l}0.37 \\
(0.41)\end{array}$ & $\begin{array}{l}0.11 \\
(0.29)\end{array}$ \\
\hline Identifies with target ethnicity ${ }^{*}$ ParticipantEastAsian & & $\begin{array}{l}-0.09^{* *} \\
(0.04)\end{array}$ & & & $\begin{array}{l}-0.24 \\
(0.20)\end{array}$ & \\
\hline Owngroup & & & $\begin{array}{l}0.07^{*} \\
(0.04)\end{array}$ & & & $\begin{array}{l}0.28^{* *} \\
(0.12)\end{array}$ \\
\hline Owngroup * ParticipantEastAsian & & & $\begin{array}{l}-0.13^{* * * *} \\
(0.04)\end{array}$ & & & $\begin{array}{l}-0.40^{* *} \\
(0.17)\end{array}$ \\
\hline Constant & $\begin{array}{l}0.22^{* * *} \\
(0.02)\end{array}$ & $\begin{array}{l}0.18^{* * *} \\
(0.02)\end{array}$ & $\begin{array}{l}0.18^{* * * *} \\
(0.02)\end{array}$ & & & \\
\hline Mean predicted value & & & & 4.60 & 4.59 & 4.59 \\
\hline Number of observations & 1089 & 1089 & 1183 & 1089 & 1089 & 1183 \\
\hline Number of participants & 363 & 363 & 396 & 363 & 363 & 396 \\
\hline
\end{tabular}

* $p<0.1$.

${ }^{* *} p<0.05$.

${ }^{* * * *} p<0.01$.

a Reported results are marginal effects $(d y / d x)$. For indicator variables, marginal effects are those associated with a discrete change in value from 0 to 1 .

b Dependent variable is an indicator that participant $i$ gave more than one-third of the total number of stickers she shared to target $j$. "Identifies with target ethnicity" defined as indicator that more than one-third of photos selected in response to perceived similarity question were from ethnic group $j$. Random person effects accounted for in estimation.

c Dependent variable is the number of stickers shared by participant $i$ with target $j$. "Identifies with target ethnicity" defined as number of photos of ethnic group $j$ in response to perceived similarity question. Standard errors clustered at the participant level.

Asian tester, 6\% with a South Asian tester, and 25\% with a Hispanic, Middle Eastern or mixed White/Korean tester. The specifications reported in the columns 2 and 5 of Table 7 include an indicator that the tester is non-white, interacted with all of the variables in our main specifications (reproduced in columns 1 and 4 of Table 6 ). The results show that tester ethnicity effects have no important effect on measured in-group bias. Interestingly, we see weak evidence that East Asian participants may share more stickers on average when they interact with a non-White tester.

Differences in socioeconomic status between White and East Asian subjects are also a potentially confounding influence. Table 8 reports the average, for each of our ethnic groups, of four neighborhood (DA)-level variables: the proportion of household heads who immigrated to Canada in the previous 5 years, the proportion whose education level is high school completion or less, the proportion whose incomes are below the low-income cutoff defined by Statistics Canada, and mean family income from all sources. Among our participants, Whites on average are drawn from relatively high socioeconomic status neighborhoods, with the lowest immigrant density, the lowest poverty rate, the fewest household heads who had not gone beyond high school, and highest mean family income.

We create a variable indicating whether a participant lived in a neighborhood that was in the bottom half of the distribution of neighborhood poverty rates among the families in our sample. The specifications reported in columns 3 and 6 of Table 7 allow all the coefficients in our main specification to differ for students living in neighborhoods in the top and bottom halves of this distribution. The results provide no evidence that differences in neighborhood income explain any of the observed differences in the behavior of White and East Asian participants.

\subsubsection{Specifications with perceived similarity}

We next explore the direct effects of children's identification with ethnic categories on their sharing behavior. The key explanatory variable in the specifications reported in Table 9 is a measure of the participant's identification with the ethnic category. In the favoritism model, we define this indicator with respect to the number of photos chosen of a given target ethnicity in response to the perceived similarity question, relative to the average number of photos selected by the 
participant in response to this question. The indicator takes on the value one if more than one-third of the total number of target photos selected by participant $i$ pertains to ethnic category $j$. Like the dependent variable, this indicator can take on the value one either never, once or twice for each participant, allowing for the possibility of ethnic identities that incorporate up to two ethnic categories. In the count model of stickers shared, we measure ethnic identification as the number of target photos selected from the ethnic category in response to the perceived similarity question.

The results in column 1 of Table 9 show that our indicator of ethnic identification alone explains none of the variation across participants and recipients in favoritism as measured by our indicator variable. When we relax the constraint that the sharing behavior of White and East Asian children is the same in column 2, we see that White children more frequently favor recipient ethnicities if they identify with them, but East Asian children do not $(p=.45)$. This difference between White and East Asian children in the association of ethnic identity and in-group bias in sharing behavior is statistically significant $(p=.04)$.

The results in columns 4 and 5 correspond to the number of stickers shared, where ethnic identification is likewise defined as a count variable (number of photos selected in response to perceived similarity question). In this case, we see in column 4 a statistically significant relationship between the intensity of ethnic identification and the number of stickers shared in the pooled sample. In other words, the average participant in the sample shares more stickers with recipients from ethnic categories that they identify more strongly with. Column 5 shows that this behavior is strong and statistically significant among Whites, and weaker and statistically insignificant among East Asians $(p=.47)$.

\section{Conclusion}

Our results confirm previous research that demonstrates that young children, like adults, engage in altruistic behavior and show a strong tendency towards egalitarianism. We gain further insight into sharing behavior by examining whether children show a preference for their social in-group when they deviate from an equal allocation of stickers across the three targets. We find clear evidence that participants from the majority White category behave more altruistically towards a White recipient than either an East Asian or South Asian recipient. Together with strong, independent evidence that White children identify with the White ethnic category, this result is consistent with the predictions of social identity theory. The statistically significant relationship between the indicator of ethnic identity and the indicator of favoritism provides direct support for the hypothesis that ethnic identity influences altruism among White children. While they evaluate the South Asians somewhat less favorably than East Asians in terms of sociability and competence, White children do not identify more with one out-group than the other, and do not favor one out-group more frequently than the other when allocating stickers in the dictator game. These results are consistent with Brewer's (1999) conclusion that in-group attachment is psychologically primary, and attitudes towards out-groups are not.

The estimated differences across recipients in the number of stickers shared by White participants is quantitatively small; on average they shared less than one-third of a sticker more with the White recipient compared to the two out-group recipients. Whether this result indicates that ethnic identity is an important or unimportant determinant of children's behavior is a matter of interpretation. While small, the fact that an effect is detectable in an experimental set-up where children's sense of egalitarianism may be primed - both by being shown the three photos simultaneously and by being assessed in the context of school social environments that typically emphasize fairness - could be viewed as evidence that ethnic identity is a powerful factor shaping altruistic preferences among White children.

The results for East Asian children exhibit a different pattern. Unlike Whites, East Asians' social identities extend beyond their own ethnic category to include the majority White category, while still excluding the South Asian category. East Asian children's sharing behavior also does not conform to the predictions of social identity theory. Although they show substantially less egalitarianism than White participants, we find no evidence of in-group bias in the dictator game among East Asian children, and no evidence that perceived similarity plays any role in their sharing decisions. Instead, East Asian participants show bias in favor of the White and South Asian recipients relative to the East Asian recipient; East Asians are as likely as Whites to favor their own category, but twice as likely to favor each of the other categories. Again, the importance of this result, given the magnitude of the estimated effect, is a matter of interpretation.

The factors underlying these differences between children from different ethnic backgrounds are unclear. It is tempting to interpret the patterns of perceived similarity among East Asians as evidence that they are defining their social identities to include higher status or majority ethnic categories. However, the sorting task results do not reveal any stark differences in children's evaluations of the sociability or competence of Whites and East Asians that would suggest clear differences in perceived social status. Moreover, while South Asians are the lowest status of the three ethnic categories according to the sorting task evaluations, there is no evidence that South Asian participants expand their social identities to include higher status categories.

East Asian children's favoritism towards other ethnic categories is also puzzling. East Asian cultures have been characterized as "collectivist" (Hofstede, 1980) relative to more individually oriented North American cultures. Previous research has found that while participants from collective cultures may demonstrate strong in-group bias with respect to naturally occurring groups, they tend not to show in-group bias towards artificially induced group associations (e.g. Buchan, Johnson, \& Croson, 2006; Triandis, 1995). Whether the weak evidence of favoritism towards anonymous others from different ethnic categories among our East Asian participants reflects a social norm in East Asian communities remains a question for future research. 
Regardless of their underlying determinants, these clear differences in patterns of discriminatory sharing between White and East Asian participants imply that care is required when interpreting responses in experimental games played with children from a variety of ethnic backgrounds. For example, Goeree et al.'s (2010) finding that dictator offers of 10-12 year olds were no more generous when the proposer and the recipient shared the same race mirrors the results from our pooled sample (including participants from all three ethnic groups). In our study, the pooled analysis is misleading: it masks significant in-group bias among Whites and out-groups bias among East Asians. Goeree et al.'s sample is composed of girls of whom 51\% are Caucasian, 27\% Asian, and 22\% from other and mixed-race groups. Further analysis of these and other data by disaggregated ethnic groups would be interesting in light of our findings.

\section{Acknowledgments}

Mohsen Javdani and Benjamin Harris provided the geographic linkage between our experimental data and Census information about neighborhood characteristics. We are grateful to Brian Krauth and Michele Battisti for helpful comments. Financial support was provided by Metropolis British Columbia and Simon Fraser University's Community Trust Endowment Fund.

\section{Appendix A. Coding of neighborhood characteristics}

Neighborhood characteristics are based on public-use aggregates of the Census of Population "long form," administered by Statistics Canada to one in five households in 1996 and 2001. The lowest level of geography for which Statistics Canada produced aggregate statistics based on the 2001 Census is a Dissemination Area (DA). DAs are geographic areas designated for the collection of Census data. DAs are composed of one or more neighboring blocks with a population of 400-700 persons.

We link postal codes to DAs using Statistics Canada's Postal Code Conversion File (PCCF). The PCCF contains a complete longitudinal correspondence between postal codes and DAs (postal codes are occasionally retired and subsequently recycled). Postal codes are smaller than DAs and usually lie entirely within a DA. In cases where postal code boundaries span multiple DAs, we use the PCCF's Single Link Indicator (which identifies the best link to an DA) to link to a unique DA.

We were unable to assign DA-level characteristics to residential postal codes in 20 cases. This arose when residential postal codes did not appear in the PCCF (most likely due to misreported postal codes), or when DA-level characteristics were suppressed by Statistics Canada for confidentiality reasons.

\section{References}

Aboud, F. E. (1988). Children and prejudice. New York: Blackwell.

Aboud, F. E., \& Doyle, A. B. (1996). Does talk of race foster prejudice or tolerance in children? Canadian Journal of Behavioural Science, 28, 161-170.

Ambady, N., Shih, M., Kim, A., \& Pittinsky, T. L. (2001). Stereotype susceptibility in children: Effects of identity activation on quantitative performance. Psychological Science, 12(5), 385-390.

Benenson, J. F., Pascoe, J., \& Radmore, N. (2007). Children's altruistic behavior in the dictator game. Evolution and Human Behavior, $28,168-175$.

Benjamin, Daniel J., Choi, James J., \& Strickland, Joshua A. (2010). Social identity and preferences. American Economic Review, $100(4), 1913-1928$.

Benjamin, Daniel J., Choi, James J., \& Geoffrey Fisher (2010). Religious identity and economic behavior. NBER Working Paper No. 15925, National Bureau of Economic Research.

Ben-Ner, Avner, McCall, Brian P., Stephane, Massoud, \& Wang, Hua (2009). Identity and in-group/out-group differentiation in work and giving behaviors: Experimental evidence. Journal of Economic Behavior and Organization, 72, 153-170.

Bernhard, Helen, Fischbacher, Urs, \& Fehr, Ernst (2006). Parochial altruism in humans. Nature, 442, $912-915$.

Bettinger, E., \& Slonim, R. (2006). Using experimental economics to measure the effects of a natural educational experiment on altruism. Journal of Public Economics, 90, 1625-1648.

Blanz, M., Mummendey, A., Mielke, R., \& Klink, A. (1998). Responding to negative social identity: A taxonomy of identity management strategies. European Journal of Social Psychology, 28(5), 697-729.

Brewer, M. B. (1999). The psychology of prejudice. In-group love or out-group hate? Journal of Social Issues, 55(3), 429-444.

Buchan, Nancy R., Johnson, Eric J., \& Croson, Rachel T. A. (2006). Let's get personal: An international examination of the influence of communication, culture and social distance on other regarding preferences. Journal of Economic Behavior and Organization, 60, 373-398.

Burns, Justine (in press). Race and social interactions in post-apartheid South Africa. In K. Newmann \& M. Centeno (Eds.), Discrimination in an unequal world. Oxford University Press.

Camerer, C. F. (2003). Behavioral game theory: Experiments in strategic interaction. Princeton, NJ: Princeton University Press.

Chen, Yan, \& Li, Sherry (2009). Group identity and social preferences. American Economic Review, 99(1), 431-457.

Clark, K. B., \& Clark, M. P. (1939). The development of consciousness of self and the emergence of racial identification in Negro preschool children. Journal of Social Psychology, 10, 591-599.

Clark, K. B., \& Clark, M. P. (1947). Racial identifications and preference in Negro children. In T. M. Newcomb \& E. L. Hartley (Eds.), Readings in social psychology (pp. 169-178). New York: Holt, Rinehart and Winston.

Clark, K. B., \& Cook, S. W. (1988). Prejudice and your child. Connecticut: Wesleyan University Press.

Corenblum, B., \& Annis, R. C. (1993). Development of racial identity in minority and majority children: An affect discrepancy model. Canadian Journal of Behavioral Science, 19, 254-265.

Eckel, Catherine C., \& Petrie, Ragan (2011). Face value. American Economic Review, 101(4), 1497-1513.

Fehr, E., Bernhard, H., \& Rockenbach, B. (2008). Egalitarianism in young children. Nature, 454, 1079-1083.

Fershtman, Chaim, \& Gneezy, Uri (2001). Discrimination in a segmented society: An experimental approach. Quarterly Journal of Economics, 116(1), 351-377.

Fong, Christina M., \& Luttmer, Enzo F. P. (2009). What determines giving to Hurricane Katrina victims? Experimental evidence on racial group loyalty. American Economic Journal: Applied Economics, 1(2), 64-87.

Goeree, Jacob K., McConnell, Margaret A., Mitchell, Tiffany, Tromp, Tracey, \& Yariv, Leeat (2010). The 1/d law of giving. American Economic Journal: Microeconomics, 2, 183-203. 
Goette, L., Huffman, D., \& Meier, S. (2006). The impact of group membership on cooperation and norm enforcement: Evidence using random assignment to real social groups. American Economic Review, 96(2), 212-216.

Gummerum, M., Keller, M., Takezawa, M., \& Mata, M. (2008). To give or not to give: Children's and adolescents' sharing and moral negotiations in economic decision situations. Child Development, 79, 562-576.

Gummerum, Michaela, Takezawa, Masanori, \& Keller, Monika (2009). The influence of social category and reciprocity on adults' and children's altruistic behavior. Evolutionary Psychology, 7(2), 295-316.

Harbaugh, W. T., Krause, K., \& Liday, S. (2003). Bargaining by children. Unpublished manuscript.

Harbaugh, W. T., \& Krause, K. (2000). Children's altruism in public good and dictator experiments. Economic Inquiry, 38, 95-109.

Hofstede, G. H. (1980). Culture's Consequences. Berkeley, CA: University of California Press.

Hornsey, M., \& Hogg, M. (2000). Assimilation and diversity: An integrative model of subgroup relations. Personality and Social Psychology Review, 4(2), $143-156$.

Hornsey, M., \& Hogg, M. (2002). The effects of status on subgroup relations. British Journal of Social Psychology, 41(2), $203-218$.

Katz, D., \& Braly, K. (1933). Racial stereotypes of one hundred college students. Journal of Abnormal and Social Psychology, 59, 436-439.

Kollock, Peter (1998). Transforming social dilemmas: Group identity and cooperation. In Peter A. Danielson (Ed.), Modeling rationality, morality and evolution (pp. 186-210). Oxford: Oxford University Press.

Martin, C. L., Ruble, D. N., \& Szkrybalo, J. (2002). Cognitive theories of early gender development. Psychological Bulletin, 128, $903-933$.

McGillicuddy-de Lisi, A. V., Daly, M., \& Neal, A. (2006). Children's distributive justice judgements: Averse racism in Euro-American children? Child development, 77, 1063-1080.

Messick, D. M. (1993). Equality as a decision heuristic. In B. A. Mellers \& J. Baron (Eds.), Psychological perspectives on justice. New York: Cambridge University Press.

Nessdale, D., Maass, A., Griffiths, J., \& Durkin, K. (2003). Effects of in-group and out-group ethnicity on children's attitudes towards members of the in-group and out-group. British Journal of Developmental Psychology, 21, 177-192.

Shih, Margaret, Pittinsky, Todd L., \& Ambady, Nalini (1999). Stereotype susceptibility: Identity salience and shifts in quantitative performance. Psychological Science, 10(1), 81-84.

Spielman, D. A. (2000). Young children, minimal groups and dichotomous categorization. Personality and Social Psychology Bulletin, $26,1433-1441$.

Tajfel, Henri, \& Turner, John (1986). The social identity theory of intergroup behavior. In Stephen Worchel \& William Austin (Eds.), The social psychology of intergroup relations. Chicago: Nelson-Hall.

Triandis, H. C. (1995). Individualism and collectivism. Boulder, CO: Westview.

Wright, S. C., \& Taylor, D. M. (1995). Identity and language of the classroom: Investigating the impact of heritage versus second language instruction on personal and collective self-esteem. Journal of Educational Psychology, 87, 241-252. 